\title{
CRESCIMENTO INICIAL DE AROEIRA DO SERTÃO (Myracrodruon urundeuva Allemão) EM DIFERENTES SUBSTRATOS ${ }^{1}$
}

\begin{abstract}
Patricia Camargos Kratka ${ }^{2}$ e Carmen Regina Mendes de Araújo Correia ${ }^{3}$
RESUMO - Este trabalho buscou avaliar o crescimento de Myracrodruon urundeuva Allemão produzida em substratos preparados com lodo de esgoto, composto orgânico e esterco bovino. O trabalho foi conduzido em casa de vegetação por 120 dias no Viveiro do Centro de Referência em Conservação da Natureza e Recuperação de Áreas Degradadas - CRAD, Brasília-DF. Foram testados quatro tipos de adubos: (1) Osmocote®; (2) esterco bovino; (3) composto orgânico; e (4) lodo de esgoto seco. Cada adubo foi submetido a três composições diferentes: (1) $25 \%$, (2) $50 \%$ e (3) $75 \%$, com exceção da testemunha e do Osmocote $\AA$, totalizando 11 tratamentos com 10 repetições cada. As variáveis analisadas foram: Diâmetro do Coleto (DC), Altura da Muda (H), Número de Folhas (NF), Matéria Fresca de Parte Aérea (MFPA), Matéria Seca de Parte Aérea (MSPA), Matéria Fresca de Raiz (MFR), Matéria Seca de Raiz (MSR) e Índice de Qualidade de Dickson (IQD). As médias foram comparadas pelo teste de Tukey a 5\% de probabilidade. Os resultados indicaram interação significativa entre os tratamentos. As maiores médias foram obtidas nos tratamentos com esterco bovino, seguidas do tratamento com composto. As plantas produzidas apenas com Osmocote ${ }^{\circledR}$ e com lodo de esgoto morreram. O resultado apontou a importância de incorporar matéria orgânica ao substrato para produção de mudas de $M$. urundeuva e o composto orgânico na proporção de $25 \%$ equivale ao esterco bovino na proporção de 25,50 e $75 \%$.
\end{abstract}

Palavras-chave: Mudas florestais; Biossólidos; Compostagem.

\section{INITIAL GROWTH OF AROEIRA OF SERTÃO (Myracrodruon urundeuva Allemão) IN DIFFERENT SUBSTRATES}

\begin{abstract}
This study aimed to evaluate the growth of M. urundeuva Allemão produced on substrates prepared with sewage sludge, organic compost and cattle manure. The experiment was conducted under greenhouse conditions during 120 days in the Nursery Reference Center for Nature Conservation and Recovery of Degraded Areas - CRAD, Brasília-DF. Four types of fertilizers were tested: (1) Osmocote ${ }^{\circledR}$, (2) cattle manure, (3) organic compost and (4) dried sewage sludge. Each fertilizer was subjected to three different compositions: (1) 25\%, (2) $50 \%$ and (3) $75 \%$, except for control and Osmocote ${ }^{\circledR}$, totaling eleven treatments with ten replicates each. The variables analyzed were: Root collar diameter (RCD); Seedling height (H), Number of leaves $(N L)$; Fresh Matter of shoot (FMAP); Dried Matter of shoot (DMAP); Fresh Matter of Root (FMR), Dried Matter of Root (DMR); Dickson Quality Index (DQI). The averages were compared by Tukey test at $5 \%$ probability. The results indicated a significant interaction between treatments. The highest averages were obtained from treatments with cattle manure, followed by treatment with organic compost. The plants produced only with Osmocote ${ }^{\circledR}$ and sewage sludge died. The study pointed out the importance of incorporating organic matter in the substrate for growing seedlings of M. urundeuva and the organic compost in a proportion of $25 \%$ is equivalent to the cattle manure in the proportion of 25,50 and $75 \%$.
\end{abstract}

Keywords: Forest seedlings; Biosolids; Composting.

\footnotetext{
${ }^{1}$ Recebido em 02.12.2013 aceito para publicação em 02.02.2015.

${ }^{2}$ Universidade de Brasília, Programa de Pós-Graduação em Ciências Florestais, Brasília-DF, Brasil. E-mail: <pckratka@gmail.com>.

${ }^{3}$ Universidade de Brasília, Coordenação do Projeto Rondon/Decanato de Extensão, Brasília-DF, Brasil. E-mail:

$<$ regicarmen@gmail.com>. 


\section{INTRODUÇÃO}

Atualmente, tem crescido a demanda por produtos e serviços voltados apara a recuperação de áreas degradadas e, ou, perturbadas, em especial para produção de mudas de espécies florestais nativas. Essa demanda crescente leva à necessidade de se investir em pesquisas que aperfeiçoem a produção de mudas a baixo custo e com qualidade e que sejam capazes de atender aos objetivos dos plantios de recuperação de áreas degradadas. Nesse contexto, verificaram-se expressivos aumentos no crescimento e qualidade de mudas, por meio da adubação orgânica, o que pode proporcionar melhor desenvolvimento, influenciando positivamente a sobrevivência das mudas após o plantio (MELOTTO et al., 2009).

Estudos que visam ao uso de resíduos industriais ou urbanos para compor os substratos florestais vêm aumentando nos últimos anos. O uso dos resíduos, além de colaborar com a diminuição do problema ambiental, é alternativa viável economicamente e possui garantia de fornecimento de matéria-prima de longo prazo e baixo custo (MARTINS et al., 2011). A atividade florestal, por não envolver produção de alimentos para consumo humano, é considerada alternativa promissora para a utilização desses materiais, sem apresentar riscos à saúde.

A compostagem é um processo puramente microbiológico e natural de decomposição da matéria orgânica de origem animal ou vegetal. Para o produtor rural, a compostagem possui grande importância econômica, pois resíduos de sua propriedade são reciclados, transformando-se em fertilizantes, ou húmus, que podem ser utilizados na produção de mudas florestais. No entanto, alguns fatores devem ser observados para que o processo de compostagem seja satisfatório, como condições favoráveis de temperatura, umidade, aeração, pH, tipo de compostos orgânicos, relação carbono e nitrogênio $(\mathrm{C} / \mathrm{N})$, granulometria do material, dimensões das leiras, entre outros (OLIVEIRA et al., 2008).

A aroeira do sertão (Myracrodruon urundeuva Allemão) tem seu emprego muito difundido na construção rural, por possuir madeira resistente. No entanto, sua exploração comercial tem sido feita de forma predatória, o que a fez ser declarada espécie ameaçada de extinção pelo Ministério do Meio Ambiente, conforme Instrução Normativa MMA n ${ }^{\circ}$ 6, de 23 de setembro de 2008 (BRASIL, 2008). Assim, a aroeira do sertão tem sido estudada e recomendada para recuperação de ecossistemas degradados e, ou, perturbados, considerando seu caráter de pioneirismo. Além do mais, é uma espécie altamente exigente, do ponto de vista nutricional, necessitando de adubação com macro e micronutrientes na produção de mudas dessa espécie (MENDONÇA et al., 1999).

O objetivo geral deste trabalho foi avaliar o crescimento inicial de plantas de Myracrodruon urundeuva Allemão, produzidas em substratos preparados em diferentes proporções de lodo de esgoto, composto orgânico, esterco bovino e fertilizante químico, no intuito de comparar o crescimento das plantas com base em algumas características morfológicas (diâmetro do coleto, altura da muda, número de folhas, matéria fresca de parte aérea, matéria seca de parte aérea; matéria fresca de raiz e matéria seca de raiz; e índice de qualidade de Dickson (IQD)), submetidas a diferentes regimes de adubação, além de recomendar a dosagem adequada dos substratos analisados, para o bom desenvolvimento de mudas dessa espécie.

\section{MATERIAL E MÉTODOS}

O trabalho foi conduzido em casa de vegetação por 120 dias, entre novembro de 2012 e março de 2013, em área pertencente ao viveiro do Centro de Referência em Conservação da Natureza e Recuperação de Áreas Degradadas - CRAD, localizada no Laboratório da Termobiologia da Universidade de Brasília, no Distrito Federal. A área do trabalho localiza-se nas coordenadas $15^{\circ} 46^{\prime} 14.47^{\prime \prime S}$ e $47^{\circ} 52^{\prime} 05.51$ "O, a uma altitude de $1.045 \mathrm{~m}$. O clima da região é Aw de Köppen (tropical chuvoso), com temperatura média anual entre 20 e $22^{\circ} \mathrm{C}$ e com precipitação anual média entre 1.300 e $1.700 \mathrm{~mm}$.

Quatro tipos de adubos foram testados: (1) dose de $8 \mathrm{~g} / \mathrm{dm}^{3}$ de Osmocote ${ }^{\circledR}$ - fertilizante peletizado (N; $\mathrm{P}_{2} \mathrm{O}_{5} ; \mathrm{K}_{2} \mathrm{O}-15-9-12$ ) de liberação lenta (5-6 meses) -, seguindo recomendação do fabricante para desenvolvimento de mudas nativas; (2) esterco bovino obtido em loja especializada, em saco com $50 \mathrm{~kg}$ já curtido; (3) composto orgânico preparado no viveiro do CRAD; e (4) lodo de esgoto seco recolhido na ETE Melchior/CAESB, Samambaia, Distrito Federal.

A amostra de solo usada para compor o substrato foi retirada da camada subsuperficial $(20-40 \mathrm{~cm}) \mathrm{de}$ um Latossolo Vermelho-Amarelo sob Cerrado sentido restrito, localizado na Fazenda Água Limpa, pertencente

Revista Árvore, Viçosa-MG, v.39, n.3, p.551-559, 2015

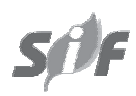


à Universidade de Brasília, Distrito Federal (1557’16.0" S; $\left.47^{\circ} 55^{\prime} 52,4^{\prime \prime} \mathrm{W}\right)$. A amostra de solo foi previamente peneirada e, depois, misturada à areia lavada, na proporção de $3: 1 / 2$, em volume, para todos os tratamentos. Todos os adubos, com exceção do Osmocote $\AA$, foram peneirados em malha de $4 \mathrm{~mm}$, antes de serem misturados à porção de solo + areia lavada. A mistura foi feita manualmente, com o auxílio de enxada, sobre lona plástica de uso único, para cada tratamento de adubo.

A composteira foi montada no CRAD, em julho de 2012, conforme metodologia descrita por Correia e Morais (2006), contendo os seguintes materiais: esterco de ovelha, cama de bovino e equino, restos vegetais frescos da CEASA, poda de árvores e folhas de bambu triturados e resíduos de composteiras anteriores produzidas no CRAD e na Fazenda Água Limpa. As leiras foram reviradas semanalmente no primeiro mês e quinzenalmente na fase mesófila. De julho a setembro, ela foi monitorada pela umidade e temperatura, em que o processo final de cura se deu em novembro de 2012.

Os substratos continham três composições diferentes dos adubos orgânicos: (1) 25\%, (2) 50\% e

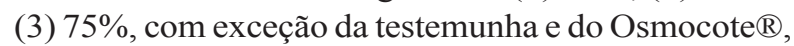
totalizando 11 tratamentos com 10 repetições cada, assim distribuídos: T1: solo + areia (3:1/2); T2: solo + areia $(3: 1 / 2)+$ osmocote; T3-A: solo + areia $(3: 1 /$ 2) $+25 \%$ de esterco bovino; T3-B: solo + areia (3:1/ 2) $+50 \%$ de esterco bovino; T3-C: solo + areia $(3: 1 /$ 2) $+75 \%$ de esterco bovino; T4-A: solo + areia (3:1/ 2) $+25 \%$ de composto orgânico; T4-B: solo + areia $(3: 1 / 2)+50 \%$ de composto orgânico; T4-C: solo + areia $(3: 1 / 2)+75 \%$ de composto orgânico; T5-A: solo + areia $(3: 1 / 2)+25 \%$ de lodo de esgoto; T5-B: solo + areia $(3: 1 / 2)+50 \%$ de lodo de esgoto; e T5-C: solo + areia $(3: 1 / 2)+75 \%$ de lodo de esgoto.

As variáveis analisadas foram: Diâmetro do coleto (DC); Altura da Muda (H); Número de Folhas (NF); Matéria Fresca de Parte Aérea (MFPA); Matéria Seca de Parte Aérea (MSPA); Matéria Fresca de Raiz (MFR); Matéria Seca de Raiz (MSR); e Índice de Qualidade de Dickson (IQD). Os componentes dos substratos testados foram submetidos à análise química, conforme protocolos do laboratório credenciado escolhido. Os resultados estão na Tabela 1 .

As sacolas plásticas utilizadas tinham as dimensões de $18 \mathrm{~cm}$ de altura e $8 \mathrm{~cm}$ de diâmetro, contendo um volume total de substrato de 904,78 mL. As sacolas foram preenchidas manualmente com os materiais misturados previamente nas devidas proporções, observando-se a compactação desses elementos. Após o preenchimento e antes do transplantio, todo o volume foi irrigado até a total umidificação do substrato.

As sementes de Myracrodruon urundeuva Allemão foram coletadas em aproximadamente 20 indivíduos provenientes da região de Cavalcante, $\mathrm{GO}$, em outubro de 2012, e doadas ao CRAD. Essas sementes foram semeadas manualmente, sem tratamento prévio, em bandejas de fitocela contendo vermiculita. Foram colocadas duas sementes a $0,5 \mathrm{~cm}$ de profundidade, em cada célula. Quando as plântulas apresentavam um par de folhas (cerca de 15 dias), elas foram transplantadas para as sacolas plásticas contendo os substratos, nos tratamentos citados. A irrigação foi realizada manualmente, uma vez por dia, com água destilada na quantidade de $50 \mathrm{~mL}$ por unidade experimental. Utilizou-se o delineamento experimental inteiramente casualizado com 10 repetições. A escolha dessa espécie baseou-se no seu alto grau de exigência nutricional e no fato de ser espécie ameaçada de extinção.

O rodízio das unidades experimentais foi realizado a cada 15 dias. Alternadamente ao rodízio a cada 15 dias, tomaram-se as medidas de diâmetro do coleto e a altura das plantas, assim como a contagem do número de folhas. O diâmetro do coleto foi tomado com o auxílio de um paquímetro digital $(0,01 \mathrm{~mm})$, sendo a altura medida com o auxílio de uma régua graduada, desde o coleto até a inserção do primeiro par de folhas.

As unidades amostrais foram cortadas no coleto, separando-se parte aérea e raiz, para obtenção dos dados de matéria seca e matéria fresca. Para obtenção da matéria fresca, a parte aérea foi pesada e acondicionada em embalagens de papel, enquanto as raízes foram cuidadosamente separadas do substrato, com o auxílio de peneira e pinça, lavadas em água corrente. Ambos os materiais foram pesados em balança analítica (precisão $0,01)$ e submetidos à secagem em estufa a $70^{\circ} \mathrm{C}$, por $72 \mathrm{~h}$. Após esse período, os materiais foram pesados para obtenção da matéria seca.

Para avaliar a qualidade das plantas, foi calculado o Índice de Qualidade de Dickson - IQD, em razão da altura da parte aérea (ALT), do diâmetro do coleto (DIAM), da matéria seca da parte aérea (MSPA), da matéria seca das raízes (MSR) e da matéria seca total (MST), por meio da fórmula:

Revista Árvore, Viçosa-MG, v.39, n.3, p.551-559, 2015 


$$
I Q D=\frac{M S T(\mathrm{~g})}{\frac{A L T(\mathrm{~cm})}{\operatorname{DIAM}(\mathrm{mm})}+\frac{\operatorname{MSPA}(\mathrm{g})}{\operatorname{MSR}(\mathrm{g})}}
$$

Os dados foram submetidos à Análise de Variância e as médias, comparadas pelo teste de Tukey a 5\% de probabilidade, utilizando o programa estatístico $\mathrm{R}$ versão 3.0.

\section{RESULTADOS}

Das 110 amostras cultivadas, apenas 68 sobreviveram. Nos tratamentos com adubação química (T2) e com lodo de esgoto (T5A, T5B e T5C), as plantas morreram após 15 dias do transplantio, restando apenas as que foram transplantadas nos tratamentos sem adubação (T1) com esterco de gado (T3A, T3B, T3C) e composto (T4A, T4B, T4C).

Os resultados da análise de variância indicam interação significativa entre os tratamentos (Tabela 2). Observou-se que as plantas que apresentaram as maiores médias em diâmetro do coleto foram as cultivadas nos tratamentos com esterco bovino (Tabela 3), e as médias desses tratamentos não diferiram estatisticamente do tratamento com composto a $25 \%$ (T4A). O tratamento sem adubação (T1) apresentou a menor média para DC, com valor semelhante aos obtidos nos tratamentos com composto a $50 \%$ e $75 \%$.

De maneira geral, os tratamentos com esterco de gado nas três proporções (T3A, T3B e T3C) apresentaram os melhores resultados de todas as variáveis analisadas. É interessante observar que, para a variável altura $(\mathrm{H})$, o resultado do teste de Tukey não apontou diferença significativa entre os tratamentos, exceto em T1, que apresentou a menor média (Tabela 3 ).

Os resultados permitiram observar que, das oito variáveis analisadas, cinco (DC, NF, MFPA, MSPA, IQD) apontaram que os tratamentos com esterco de gado (T3A, T3B e T3C) são estatisticamente iguais ao tratamento com composto $25 \%$ (T4A) (Tabela 3 ).

Para todas as variáveis analisadas, o tratamento sem adubação foi o que apresentou os resultados mais baixos, estatisticamente considerados iguais aos dos tratamentos com composto a 50\% e 75\% (T4B e T4C).

\section{DISCUSSÃO}

A morte de todas as plantas tratadas com adubo químico indica que a dosagem utilizada neste trabalho foi alta, mesmo sendo a indicada pelo fabricante para produção de espécies nativas. Tal fato pode ter levado à fitotoxicidade, cujos sintomas mais evidentes são a clorose e a necrose foliar, sendo esta última observada neste trabalho, nas mudas cultivadas no tratamento sem adubação.

Em experimento semelhante ao aqui apresentado, Scheer et al. (2012a,b) analisaram o desenvolvimento de Lafoensia pacari e Anadenanthera colubrina em substrato composto por lodo de esgoto aeróbio compostado com podas de árvores trituradas, com diferentes níveis de fertilização, a saber: 1) testemunha (sem fertilizante); 2) dose-padrão (2,7 g de fertilizante granulado (N; $\mathrm{P}_{2} \mathrm{O}_{5}$; e $\mathrm{K}_{2} \mathrm{O}-15-9-12$ ) de liberação lenta (5-6 meses) por $\mathrm{dm}^{3}$ ); e 3 ) dose alta (4 g de fertilizante granulado (N; $\mathrm{P}_{2} \mathrm{O}_{5}$; e $\mathrm{K}_{2} \mathrm{O}$ - 15-9-12) de liberação lenta (5-6 meses) por $\mathrm{dm}^{3}$ ). A dose-padrão de fertilizantes refere-se ao que é utilizado em viveiros da Companhia de Saneamento do Paraná (SANEPAR), enquanto a dose de $4 \mathrm{~g} / \mathrm{dm}^{3}$ foi escolhida para verificar se maiores níveis de fertilizante resultam em maior crescimento de mudas. Esses autores concluíram que a dose menor de $2,7 \mathrm{~g} / \mathrm{dm}^{3}$ de fertilizante é capaz de promover crescimento adequado às mudas, obtendo resultados bastante próximos aos da adubação com $4 \mathrm{~g} / \mathrm{dm}^{3}$, na maioria das variáveis testadas no experimento (altura, diâmetro do coleto e massa seca da parte aérea (folhas e ramos)), representando economia de fertilizante.

Verificou-se que a dose de fertilizante químico utilizada neste trabalho $\left(8,0 \mathrm{~g} / \mathrm{dm}^{3}\right)$ foi o dobro da maior dosagem utilizada por Scheer et al. (2012a,b), e não foram encontrados, na literatura, estudos que confirmassem essa recomendação, apesar de isso ter sido constatado na embalagem do fabricante. Dessa forma, recomenda-se que novos experimentos sejam realizados, a fim de testar diferentes dosagens de Osmocote ${ }^{\circledR}$ para produção de mudas de M. urundeuva.

Quanto às plantas mortas com tratamento de lodo de esgoto, observou-se que o lodo recolhido na CAESB não estava estabilizado. Sabe-se que o único tratamento que o lodo recebeu na ETE Melchior foi a secagem a pleno sol, em pátio aberto, sendo o material revolvido a cada semana, com a ajuda de retroescavadeira. Quando da irrigação das plantas transplantadas para os tratamentos com esse componente, a água reativou a ação dos microrganismos. Observou-se que os substratos se aqueceram e o volume aumentou até extravasar os recipientes, além de desenvolverem mau 
cheiro. Essas características indicam atividade microbiana, o que pode ter ocasionado a morte das plantas (SAITO, 2007).

Outra questão relevante é que a análise química do lodo de esgoto indicou baixa relação $\mathrm{C} / \mathrm{N}(7,7)$, o que, por sua vez, também pode favorecer a atividade microbiana. Cerri et al. (2008) consideram que os limites de 26/1 a 35/1 são os mais recomendados para uma rápida e eficiente compostagem. Segundo esses autores, resíduos com relação $\mathrm{C} / \mathrm{N}$ baixa, como observado no lodo (Tabela 1), perdem nitrogênio na forma amoniacal durante o processo de compostagem, prejudicando a qualidade do composto. Nesse caso, recomenda-se juntar restos vegetais celulósicos para elevar essa fórmula a um valor próximo do ideal.

Neste trabalho, observou-se que o lodo de esgoto, da maneira como é tratado na CAESB (ETE Melchior), não é recomendado para a produção de mudas. Ademais, Scheer et al. (2012a,b) indicaram o uso de lodo de esgoto associado a algum outro tipo de matéria orgânica, como poda de árvore triturada, na composição do substrato para produção florestal e, principalmente, utilizado após o processo de compostagem.

No trabalho desenvolvido por Scheer et al. (2012a,b), foi empregado o lodo de esgoto compostado. Esse material foi misturado em betoneiras, em diferentes proporções, com resíduos de podas de árvores triturados e dispostas em leiras estáticas aeradas de aproximadamente 1,1 $\mathrm{m}$ de altura, 2,2 $\mathrm{m}$ de base e 4 $\mathrm{m}$ de comprimento, em que, após quatro meses, os compostos já estavam prontos para uso. Dessa forma, acredita-se que, no caso específico do lodo de esgoto da CAESB, ele deve, primeiramente, receber algum tratamento de estabilização que neutralizasse a ação dos microrganismos, para depois ser utilizado como

Tabela 1 - Análises químicas dos tratamentos e do solo (dezembro/2012).

Table 1 - Chemical analyzes of treatments and soil (December 2012).

\begin{tabular}{|c|c|c|c|c|c|c|c|}
\hline \multirow{2}{*}{ Característica $^{\mathrm{s}}$} & \multicolumn{2}{|c|}{ Esterco bovino } & \multicolumn{2}{|c|}{ Composto orgânico } & \multicolumn{2}{|c|}{ Lodo de esgoto } & \multirow{2}{*}{$\begin{array}{c}\text { Solo } \\
\text { Base úmida } \\
\end{array}$} \\
\hline & Base seca & Base úmida & Base seca & Base úmida & Base seca & Base úmida & \\
\hline $\mathrm{pH}$ & 6,3 & 6,3 & 6,9 & 6,9 & 6,3 & 6,3 & 5,66 \\
\hline Umidade $\left(65^{\circ} \mathrm{C}\right)(\%)$ & 34,6 & - & 49,5 & - & 7,6 & - & - \\
\hline Matéria orgânica (\%) & 70,8 & 46,3 & 27,4 & 17,9 & 54,4 & 35,6 & 1,30 \\
\hline Nitrogênio (N) (\%) & 3,06 & 2 & 1,09 & 0,71 & 3,91 & 2,56 & 0,03 \\
\hline Fósforo total (P) (\%) & 0,53 & 0,35 & 0,33 & 0,22 & 0,28 & 0,18 & 0,03 \\
\hline Potássio (K) (\%) & 0,61 & 0,4 & 0,56 & 0,37 & 0,56 & 0,37 & 0,28 \\
\hline Cálcio (Ca) (\%) & 1,57 & 1,03 & 1,76 & 1,16 & 1,47 & 0,96 & 10,00 \\
\hline Magnésio (Mg) (\%) & 0,39 & 0,25 & 0,51 & 0,33 & 0,52 & 0,34 & Traços \\
\hline Enxofre (S) (\%) & 0,32 & 0,21 & 0,28 & 0,18 & 0,35 & 0,23 & \\
\hline Carbono orgânico (C) (\%) & 39,3 & 25,7 & 15,2 & 9,9 & 30,2 & 19,8 & 72,55 \\
\hline Boro (B) (ppm) & 30,3 & 19,8 & 25 & 16,3 & 31,48 & 20,5 & \\
\hline Cobre $(\mathrm{Cu})(\mathrm{ppm})$ & 0,4 & 0,3 & 6,7 & 4,4 & 11,7 & 7,6 & \\
\hline Ferro (Fe) (ppm) & 4.298 & 2.809 & 14.648 & 9.573 & 14.130 & 9.234 & \\
\hline Manganês (Mn) (ppm) & 121 & 79 & 102 & 67 & 54 & 35 & \\
\hline Zinco $(\mathrm{Zn})(\mathrm{ppm})$ & 88 & 58 & 57,8 & 38 & 530 & 346 & \\
\hline \multicolumn{8}{|l|}{ Condutividade } \\
\hline Elétrica (CE, dS/m) & 0,2 & 0,2 & 0,2 & 0,2 & 0,5 & 0,5 & 0,018 \\
\hline CTC (mE/100 g) & 67 & 43 & 65 & 42 & 63 & 41 & \\
\hline Relação C/N & 12,9 & 8,4 & 14 & 9,1 & 7,7 & 5,1 & \\
\hline DQO (mg/g) & 1.049 & 685 & 406 & 265 & 806 & 527 & \\
\hline Alumínio (Al) & \multicolumn{2}{|c|}{ N.A. } & \multicolumn{2}{|c|}{ N.A. } & \multicolumn{2}{|c|}{ N.A. N.A. } & \multirow{9}{*}{$\begin{array}{c}\text { Traços } \\
3,63\end{array}$} \\
\hline $\mathrm{H}^{+}+\mathrm{Al}^{3+}\left(\mathrm{mmol}_{\mathrm{c}} / \mathrm{dm}^{3}\right)$ & \multicolumn{2}{|c|}{ N.A. } & \multicolumn{2}{|c|}{ N.A. } & & & \\
\hline Arsênio (As) (mg/kg) & \multicolumn{2}{|c|}{0,0005} & \multicolumn{2}{|c|}{0,0005} & \multicolumn{2}{|c|}{0,0005} & \\
\hline Cádmio (Cd) (mg/kg) & \multicolumn{2}{|c|}{0,01} & \multicolumn{2}{|c|}{0,01} & \multicolumn{2}{|c|}{0,01} & \\
\hline Chumbo (Pb) (mg/kg) & \multicolumn{2}{|c|}{0,1} & \multicolumn{2}{|c|}{0,01} & \multicolumn{2}{|c|}{0,01} & \\
\hline Cromo (Cr) (mg/kg) & \multicolumn{2}{|c|}{0,1} & \multicolumn{2}{|c|}{0,01} & \multicolumn{2}{|c|}{0,01} & \\
\hline Níquel (Ni) (mg/kg) & \multicolumn{2}{|c|}{0,01} & \multicolumn{2}{|c|}{0,01} & \multicolumn{2}{|c|}{0,01} & \\
\hline Mercúrio $(\mathrm{Hg})(\mathrm{mg} / \mathrm{kg})$ & \multicolumn{2}{|c|}{0,030} & \multicolumn{2}{|c|}{0,030} & \multicolumn{2}{|c|}{0,030} & \\
\hline Selênio (Se) (mg/kg) & & 48 & & 48 & & 48 & \\
\hline
\end{tabular}


fonte de macro e micronutrientes na produção de mudas florestais.

A análise química dos compostos orgânicos (Tabela 1) permitiu observar que, entre todos os materiais utilizados, o esterco de gado apresentou o maior teor de matéria orgânica $\left(70,8 \mathrm{~g} / \mathrm{dm}^{3}\right)$, enquanto o composto, o menor $\left(27,4 \mathrm{~g} / \mathrm{dm}^{3}\right)$. No entanto, mesmo com baixo teor de matéria orgânica, o tratamento com composto a $25 \%$ apresentou resultados estatisticamente iguais aos dos tratamentos com esterco de gado nas três proporções (Tabela 3). Esse fato pode ser explicado pelo fato de que os adubos orgânicos, além de fornecerem nutrientes às plantas, atuam como condicionadores que melhoram as características físicas do solo e, portanto, a absorção de nutrientes, levando ao bom desenvolvimento vegetal (KÄMPF, 2005). Maria et al. (2007) avaliaram a aplicação do lodo de esgoto como condicionador do solo, por meio de seu efeito sobre a agregação do solo agrícola, visando à sua utilização na recuperação de áreas degradadas, concluindo que esse adubo agiu como condicionador, melhorando a agregação do solo.

Os resultados deste trabalho permitiram indicar que a incorporação de matéria orgânica no substrato melhora significativamente o desenvolvimento da planta, uma vez que o tratamento sem adubação apresentou médias significativamente mais baixas em todas as variáveis analisadas (Tabela 3 ). Segundo Caldeira et al. (2008), a matéria orgânica é um dos componentes fundamentais dos substratos, pois possui a finalidade básica de aumentar a capacidade de retenção de água e nutrientes para as mudas, além de apresentar outras vantagens, como: redução na densidade aparente e global e aumento da porosidade do meio. Esses mesmos autores, avaliando o desenvolvimento de mudas de aroeira-vermelha (Schinus terebinthifolius Raddi) e utilizando composto orgânico no substrato, concluíram que mudas produzidas com altas proporções de composto orgânico (100\%) no substrato tiveram efeito negativo, tanto no comprimento de raiz quanto na produção de biomassa seca de raiz, o que corrobora os resultados aqui apresentados.

O maior crescimento em diâmetro do coleto foi observado nos tratamentos com esterco bovino nas três proporções, obtendo-se 3,80 mm na proporção de $25 \%$; 3,73 $\mathrm{mm}$ a $50 \%$; e 3,24 $\mathrm{mm}$ a $75 \%$ (Tabela 3 ). Resultados semelhantes foram apontados por Artur et al. (2007). Esses autores, testando quatro níveis de adubação (correspondentes a 0, 2, 4 e 6 partes que, em massa, equivalem a $0,101,175$ e $229 \mathrm{~kg} \mathrm{~m}^{-3}$ ) com esterco bovino em mudas de guanandi (Calophyllum brasiliense Cambèss), obtiveram valores médios de crescimento de diâmetro do coleto de $3,75 \mathrm{~mm}$.

Tabela 2 - Resultados da análise de variância das variáveis estudadas.

Table 2 - Results of Analysis of Variance for the studied variables.

\begin{tabular}{|c|c|c|c|c|c|}
\hline & $\mathrm{FV}$ & GL & MQ & $\mathrm{F}$ & Valor-P \\
\hline \multirow[t]{2}{*}{$\mathrm{DC}$} & Substrato & 6 & 9,195 & 14,8 & $2,36 \mathrm{e}-10 * *$ \\
\hline & $\mathrm{DC}$ & 61 & 0,621 & & \\
\hline \multirow[t]{2}{*}{$\mathrm{H}$} & Substrato & 6 & 22,157 & 35,665 & $5,52 \mathrm{e}-11 * *$ \\
\hline & $\mathrm{H}$ & 61 & 0,621 & & \\
\hline \multirow[t]{2}{*}{ NF } & Substrato & 6 & 2,526 & 9,16 & $0,000332 * *$ \\
\hline & $\mathrm{NF}$ & 61 & 0,2758 & & \\
\hline \multirow[t]{2}{*}{ MFPA } & Substrato & 6 & 33,38 & 10,23 & $8,19 \mathrm{e}-08 * *$ \\
\hline & MFPA & 61 & 3,26 & & \\
\hline \multirow[t]{2}{*}{ MSPA } & Substrato & 6 & 2,7946 & 10,46 & $5,97 \mathrm{e}-08 * *$ \\
\hline & MSPA & 61 & 0,2672 & & \\
\hline \multirow[t]{2}{*}{ MFR } & Substrato & 6 & 8,59 & 7,459 & $5,15 \mathrm{e}-06 * *$ \\
\hline & MFR & 61 & 1,153 & & \\
\hline \multirow[t]{2}{*}{ MSR } & Substrato & 6 & 0,28423 & 7,183 & $8 \mathrm{e}-06 * *$ \\
\hline & MSR & 61 & 0,03957 & & \\
\hline \multirow[t]{2}{*}{ IQD } & Substrato & 6 & 0,3383 & 6,841 & $1,39 \mathrm{e}-05 * *$ \\
\hline & IQD & 61 & 0,0495 & & \\
\hline
\end{tabular}

** Significativo a 5\%. DC: diâmetro do coleto $(\mathrm{mm}) ; \mathrm{H}$ : altura (cm); NF: número de folhas; MFPA: matéria fresca de parte aérea (g); MSPA: matéria seca de parte aérea (g); MFR: matéria fresca de raiz (g); MSR: matéria seca de raiz (g); e IQD: Índice de Qualidade de Dickson.

Revista Árvore, Viçosa-MG, v.39, n.3, p.551-559, 2015 
Tabela 3 - Médias das variáveis analisadas por tratamento, comparadas pelo teste de Tukey a 5\% de probabilidade. Table 3 - Averages of the assessed variables for treatments compared by Tukey test at 5\% probability.

\begin{tabular}{lcccccccc}
\hline & DC & H & NF & MFPA & MSPA & MFR & MSR \\
\hline T 1 & $1,44 \mathrm{~b}$ & $2,32 \mathrm{~b}$ & $7,78 \mathrm{c}$ & $0,60 \mathrm{~b}$ & $0,13 \mathrm{~b}$ & $0,40 \mathrm{~b}$ & $0,06 \mathrm{~b}$ & $0,05 \mathrm{~b}$ \\
T3A & $3,80 \mathrm{a}$ & $3,27 \mathrm{a}$ & $15,40 \mathrm{a}$ & $4,86 \mathrm{a}$ & $1,37 \mathrm{a}$ & $2,51 \mathrm{a}$ & $0,46 \mathrm{a}$ & $0,52 \mathrm{a}$ \\
T3B & $3,73 \mathrm{a}$ & $3,22 \mathrm{a}$ & $16,80 \mathrm{a}$ & $4,95 \mathrm{a}$ & $1,35 \mathrm{a}$ & $2,17 \mathrm{a}$ & $0,37 \mathrm{a}$ & $0,40 \mathrm{a}$ \\
T3C & $3,24 \mathrm{a}$ & $3,03 \mathrm{a}$ & $15,20 \mathrm{a}$ & $3,67 \mathrm{a}$ & $1,04 \mathrm{a}$ & $1,61 \mathrm{a}$ & $0,27 \mathrm{a}$ & $0,28 \mathrm{a}$ \\
T4A & $3,02 \mathrm{a}$ & $3,07 \mathrm{a}$ & $14,33 \mathrm{a}$ & $3,49 \mathrm{a}$ & $0,95 \mathrm{a}$ & $1,00 \mathrm{~b}$ & $0,16 \mathrm{~b}$ & $0,17 \mathrm{a}$ \\
T4B & $2,10 \mathrm{~b}$ & $3,15 \mathrm{a}$ & $10,50 \mathrm{~b}$ & $1,72 \mathrm{~b}$ & $0,41 \mathrm{~b}$ & $0,39 \mathrm{~b}$ & $0,07 \mathrm{~b}$ & $0,06 \mathrm{~b}$ \\
T4C & $1,67 \mathrm{~b}$ & $2,86 \mathrm{a}$ & $9,50 \mathrm{~b}$ & $0,68 \mathrm{~b}$ & $0,15 \mathrm{~b}$ & $0,17 \mathrm{~b}$ & $0,02 \mathrm{~b}$ & $0,02 \mathrm{~b}$ \\
\hline
\end{tabular}

As médias seguidas da mesma letra na coluna não diferem entre si, estatisticamente, pelo teste de Tukey a 5\% de probabilidade. DC: diâmetro do coleto $(\mathrm{mm})$; H: altura $(\mathrm{cm})$; NF: número de folhas; MFPA: matéria fresca de parte aérea (g); MSPA: matéria seca de parte aérea (g); MFR: matéria fresca de raiz (g); MSR: matéria seca de raiz (g); IQD: Índice de Qualidade de Dickson; T1: tratamento sem adubação; T3A: tratamento com esterco a $25 \%$; T3B: tratamento com esterco a $50 \%$; T3C: tratamento com esterco a $75 \%$; T $4 \mathrm{~A}$ : tratamento com composto a $25 \%$; T4B: tratamento com composto a $50 \%$; e T4C: tratamento com composto a $75 \%$.

Cunha et al. (2005), analisando o desenvolvimento de Tabebuia impetiginosa (Mart. ex D.C.) Standl, observaram que as plantas cultivadas apenas com terra de subsolo apresentaram diâmetro do coleto inferior ao daquelas que receberam composto orgânico. No entanto, cabe ressaltar que neste trabalho, nos tratamentos com composto a $50 \%$ e $75 \%$, o desenvolvimento de diâmetro de coleto foi baixo, sendo comparado estatisticamente com o tratamento sem adubação. Acredita-se que tal fato possa ser explicado pela porosidade do material que foi maior que o desejado. Porém, essa característica não foi avaliada neste trabalho.

O interessante é que Daniel et al. (1997) apontaram que o diâmetro do coleto da espécie Acacia mangium em torno de 2 mm é considerado ideal para comercialização. No entanto, Gonçalves et al. (2000) consideram que o diâmetro do coleto adequado a mudas de espécies florestais de qualidade está entre 5 e $10 \mathrm{~mm}$. Neste trabalho, nenhuma das plantas apresentou valores superiores a $5 \mathrm{~mm}$. No entanto, com 120 dias as plantas cultivadas em esterco bovino (em todas as proporções) e em composto a $25 \%$ atingiram o padrão de comercialização apontado pelos primeiros autores. $\mathrm{O}$ intervalo de valores de diâmetro do coleto sugerido por Gonçalves et al. (Op. cit.) parece não ser aplicável para M. urundeuva nas condições testadas neste trabalho.

As alturas médias das plantas foram iguais estatisticamente em todos os tratamentos, com exceção daquele sem adubação. Esse resultado difere do encontrado por Caldeira et al. (2008), em que ficou evidente que a adição de esterco representou aumento no desenvolvimento em altura das plantas de Schinus terebinthifolius. Esses resultados assemelham-se aos encontrados por Carvalho Filho et al. (2003), que apontaram que plantas de Hymenaea courbaril L., produzidas em substrato de solo+areia+esterco na proporção de 1:2:1, apresentaram maiores médias de altura de planta do que as cultivadas em solo + areia na proporção $1: 1$. A média da altura das plantas foi a única variável neste trabalho que não apresentou diferença significativa entre os tratamentos com composto e esterco.

Houve diferença significativa entre os tratamentos da variável número de folhas. Neste trabalho, os tratamentos com esterco bovino nas proporções 25 , 50 e $75 \%$ obtiveram as maiores médias em número de folhas $(15,4 ; 16,8$; e 15,2 , respectivamente), que são estatisticamente iguais ao tratamento com composto a $25 \%(14,33)$. Esse resultado também foi encontrado por Carvalho Filho et al. (2002), em que os melhores resultados para número de folhas de canafístula (Cassia grandis L.) foram encontrados nos substratos compostos por solo + esterco (proporção 2:1) e solo + areia + esterco (proporção 1:2:1), com 12,4 e 12,0 folhas por planta, respectivamente. Também, Caron et al. (2007) encontraram o número médio de 15,6 folhas por planta de $M$. urundeuva, cultivadas em substrato com $1 / 3$ de matéria orgânica constituída de palha de café, em 112 dias de experimento. No entanto, Artur et al. (2007) encontraram resultados divergentes para plantas de guanandi (Calophyllum brasiliense). Esses autores observaram que o maior valor estimado (12 folhas) foi obtido no tratamento que não recebeu esterco. Cabe ressaltar que os esses autores apontaram que os resultados encontrados no guanandi contrariam as observações verificadas em outras espécies florestais. 
As menores médias de matéria seca e fresca de raiz, que foram observadas nos tratamentos com composto a 50 e $75 \%$, podem ser em decorrência da porosidade que esse material apresenta naturalmente. Quando a sua proporção na mistura com o substrato é muito alta, o desenvolvimento das raízes pode ficar prejudicado devido ao aumento da aeração no substrato (KÄMPF, 2005). Segundo essa autora, a porosidade é responsável pelas trocas gasosas entre o substrato e a atmosfera, bem como determina os movimentos da água no vaso e a drenagem.

A análise dos resultados da massa fresca e seca de parte aérea e de raiz indicou resultados semelhantes aos observados por Artur et al. (2007). Eles observaram que as médias dos parâmetros de crescimento diminuíram à medida que aumentaram a proporção de esterco bovino. A massa fresca de parte aérea (MFPA), massa fresca de raiz (MFR), massa seca de parte aérea (MSPA) e massa seca de raiz (MSR) diminuíram com o aumento de esterco bovino e de composto (Tabela 3). Caldeira et al. (2008), avaliando a influência do composto orgânico em Schinus terebinthifolius, concluíram que os resultados dos índices de qualidade de mudas produzidas com 100\% de composto orgânico, no geral, apresentaram os menores índices.

Os resultados deste trabalho para o IQD apontaram que as plantas cultivadas em esterco bovino, nas três proporções, apresentaram as maiores médias, o que permite classificá-las como as de melhor qualidade. Pode ser observado também que, tanto nos tratamentos com esterco quanto nos com composto, à medida que ocorreu o aumento na dosagem, o Índice decresceu, evidenciando que nem sempre o incremento nas doses de adubação melhora o crescimento das mudas.

De maneira geral, o tratamento com composto a $25 \%$ apresentou médias estatisticamente iguais às dos tratamentos com esterco de gado nas três proporções (Tabela 3). Assim, a elevação da dosagem tanto de composto quanto de esterco não significou aumento nos parâmetros de crescimento das plantas analisadas.

\section{CONCLUSÃO}

Neste trabalho, ficou evidenciado que o lodo de esgoto, da maneira como é ofertado pela CAESB, não pode ser utilizado na produção de mudas florestais. Mais pesquisas devem ser incentivadas no intuito de avaliar se, após a compostagem do lodo ou outro processo de inertização, esse material pode tornar-se viável para a produção de mudas florestais em viveiro.
A adubação química foi prejudicial ao desenvolvimento das plantas. A dosagem utilizada foi alta, mesmo sendo a indicada pelo fabricante para produção de mudas nativas.

Pode-se afirmar que o substrato, sem nenhuma adubação, não deve ser utilizado pelos viveiristas. Ficou evidente que a incorporação de matéria orgânica ao substrato melhora o desenvolvimento das plantas. Mesmo a incorporação da menor dosagem de composto apresentou resposta semelhante à adubação por esterco bovino em todas as proporções.

As plantas de $M$. urundeuva apresentaram melhores índices de crescimento com o esterco bovino na dosagem recomendada de $25 \%$ do substrato utilizado, haja vista que os dados apontaram que o aumento na dosagem não implica aumento dos parâmetros de crescimento analisados. Fica evidente que qualquer formulação acima desse percentual seria considerada desperdício.

Quanto ao composto, afirma-se que na proporção de $25 \%$ (T4) esse material apresentou os mesmos resultados que a adubação com esterco bovino, em todas as proporções.

\section{REFERÊNCIAS}

ARTUR, A.G.; CRUZ, M.C.P.; FERREIRA, M.E.; BARRETTO, V.C.M.; YAGI, R. Esterco bovino e calagem para formação de mudas de guanandi. Pesquisa Agropecuária Brasileira, v.42, n.6, p.843-850, 2007.

BRASIL. Ministério do Meio Ambiente.

Instrução Normativa $n^{\circ}$. 006 de 23 de setembro de 2008. Disponível em: http:// portal.saude.gov.br/portal/arquivos/pdf/ MMA_IN_N_6.pdf. Acesso em 20 abr.2013.

CALDEIRA, M.V.W.; ROSA, G.N.; FENILLI, T.A.B.; HARBS, R.M.P. Composto orgânico na produção de mudas de aroeira vermelha. Scientia Agraria, v.9, n.1, p.27-33, 2008.

CARON, B.O.; MEIRA, W.R.; SCHMIDT, D.; SANTOS FILHO, BG.; MEDEIROS, S.L.P.; MANFRON, P.; MÜLLER,L. Análise de crescimento de plantas de aroeira vermelha no município de Ji-Paraná, RO. Revista da Faculdade de Zootecnia, Veterinária e Agronomia, v.14, n.1, p.1-13, 2007. 
CARVALHO FILHO, J.L.S.; ARRIGONI-BLANK, M.F.; BLANK, A.F.; RANGEL, M.S.A.; Produção de mudas de jatobá (Hymenaea courbaril L.) em diferentes ambientes, recipientes e composição de substratos. Revista Ceres, v.9, n.1, p.109-118, 2003.

CARVALHO FILHO, J.L.S.; ARRIGONI-BLANK, M.F.; BLANK, A.F.; SANTOS NETO, A.L.; AMÂNCIO, V.F. Produção de mudas de Cassia grandis L. em diferentes ambientes, recipientes e misturas de substratos. Revista Ceres, v.40, p.341-352, 2002.

CERRI. C.E.P.; OLIVEIRA, E.C.A.; SARTORI, R.H.; GARCEZ, T.B. Compostagem 2008. Programa de Pós-Graduação em Solos e Nutrição de Plantas. Piracicaba: ESALQ, 2008.

CORREIA, C.R.M.A.; MORAIS O.M. Manual de compostagem: processo simplificado. Brasília, DF: UnB, 2006. 35p.

CUNHA, A.; ANDRADE, L.A.; BRUNO, R.L.A.; SILVA, J.A.L.S.; SOUZA, V.C. Efeitos de substratos e das dimensões dos recipientes na qualidade das mudas de Tabebuia impetiginosa (Mart. Ex D.C.) Standl. Revista Árvore, v.29, n.4, p.507-516, 2005.

DANIEL, O.; VITORINO, A.C.T.; ALOVISI, A.A.; MAZZOCHIN, L.; TOKURA, A.M.; PINHEIRO, E.R.; SOUZA, E.F. Aplicação de fósforo em mudas de Acacia mangium Wild. Revista Árvore, v.21, n.2, p.163-168, 1997.

GONÇALVES, J.L.M.; SANTARELLI, E.G.; MORAES NETO, S.P.; MANARA, M.P. Produção de mudas de espécies nativas: substrato, nutrição, sombreamento e fertilização. In: GONÇALVES, J.L.M.; BENEDETTI, V. (Ed.). Nutrição e fertilização florestal. Piracicaba: IPEF, 2000. p.309-350.

KÄMPF, A.N. Produção comercial de plantas ornamentais. 2.ed.. Agro Livros, 2005.
MARIA, I.C.; KOCSSI, M.A.; DECHEN, S.C.F. Agregação do solo em área que recebeu lodo de esgoto. Bragantia, v.66, n.2, p.291-298, 2007.

MARTINS, C.C.; MACHADO, C.G.; CALDAS, I.G.R.; VIEIRA, I.G. Vermiculita como substrato para o teste de germinação de sementes de barbatimão. Ciência Florestal, v.21, n.3, p.421-427, 2011.

MELOTTO, A.; NICODEMO M.L.; BOCCHESE, R.A.; LAURA, V.A.L.; G.NETO, M.M.; SCHLEDER, D.D.; POTT, A.; SILVA, V.P. Sobrevivência e crescimento inicial em campo de espécies florestais nativas do Brasil central indicadas para sistemas silvipastoris. Revista Árvore, v.33, n.3, p.425-432, 2009.

MENDONÇA, R.; FELFILI, J.M.; WALTER, B.M.T.; SILVA-JÚNIOR, M.C.; REZENDE, A.V.; FILGUEIRAS, T.S.; NOGUEIRA, P.E.N. Flora lenhosa do bioma Cerrado. In: SANO, S.M.; ALMEIDA, S.P. (Orgs.). Cerrado: ambiente e flora. Planaltina: EMBRAPA-Cerrados, 1999. p.287-556.

OLIVEIRA, E.C.A.; SARTORI, R.H.; GARCEZ, T.B. Compostagem. Piracicaba. Universidade de São Paulo/ESALQ, 2008.

SAITO, M.L. O uso do lodo de esgoto na agricultura: precauções com os contaminantes orgânicos. Jaguariúna: Embrapa Meio Ambiente, 2007. 35p. (Embrapa Meio Ambiente. Documentos, 64).

SCHEER, M.B.; CARNEIRO, C.; SANTOS, K.G.; BRESSAN, O.A. Crescimento e Nutrição de Mudas de Lafoensia pacari com Lodo de Esgoto. Revista Floresta e Ambiente, v.19, n.1, p.55-65, 2012a. Disponível em http:// <www.floram.org/files/v19n1/v19n1a7.pdf. Acesso $>$ em 20 jan. 2013.

SCHEER, M.B.; CARNEIRO, C.; SANTOS, K.G. Compostos de lodo de esgoto para a produção de mudas de Anadenanthera colubrina (Vell.) Brenan. Cerne, v.18, n.4, p.613-621, 2012 b. 